\title{
ORIGINAL \\ FREQUENCY OF VACCINATION IN MEASLES
}

\section{PROF-1079}

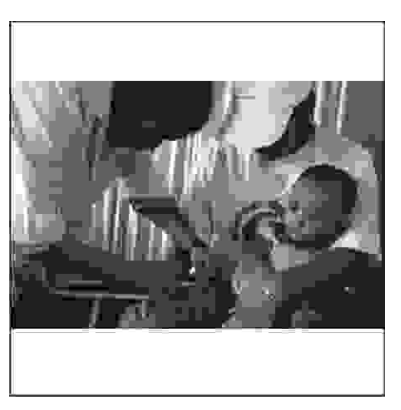

\author{
DR. FAISAL BASHEER, FCPS \\ Paediarics \\ Combined Military Hospital, \\ Pano Aqil Cantt \\ DR. SHAKEEL AHMED, FCPS \\ Combined Military Hospital, \\ Okara Cantt
}

\author{
DR. MOHAMMAD AATIF, FCPS \\ Combined Military Hospital, \\ Kharian Cantt \\ Dr. Salman Ali, FCPS \\ Military Hospital, \\ Rawalpindi
}

\begin{abstract}
Objective: To calculate the frequency of vaccinated children in measles cases and to determine association of age and sex with vaccination status of measles. Design: Descriptive Study. Place and duration of study: Department Of Paediatric Medicine, Military Hospital (MH), Rawalpindi from October 2001 to September 2002. Patients and Methods: 250 cases of clinical measles, selected by convenient sampling, reporting in out patient department or admitted were registered. Age, sex and vaccination status were noted. Statistical analyses were carried out employing "t Test" and "Chi-Square test", utilizing SPSS version 10.0 for Windows (SPSS Inc., Chicago). Test of significance was applied at a confidence limit of $95 \%$. Results: $71.6 \%$ were vaccinated and $28.4 \%$ were unvaccinated. Ages ranged from 1 to 12 years with a mean age of $5.4 \pm 2.4$ years. Vaccinated cases had a significantly $(p<0.05)$ higher mean age $(5.9 \pm 2.1)$ as compared to unvaccinated ones $(4.0 \pm 2.5)$. Majority $(46 \%)$ were $4-6$ years old. Among vaccinated $50.3 \%$ were $4-6$ years old but among the unvaccinated $52.1 \%$ were $1-3$ years of age. Male to female ratio was 1.4:1. Proportion of males was significantly more ( $p$ value $<0.05$ ) than females in both groups. Conclusion: Vaccination failure observed in this study, that is $71.6 \%$ patients contracting measles despite being vaccinated, is clearly higher than that accepted for measles vaccine $(2-10 \%)$. Though high immunization coverage $(>90 \%)$ in the first dose is still crucial for eradication there is need to revise the in-vogue vaccination schedule to reduce the incidence and so is the measles related morbidity and mortality.
\end{abstract}

Key words: Measles, Immunization, Vaccination Schedule, Eradication

\section{INTRODUCTION}

Measles has always been a widely prevalent infection even before Rhazes recognized it as a communicable disease in the $10^{\text {th }}$ century. Measles currently occurs sporadically in the advanced countries; however this disease is a scourge of children in all the developing countries, mostly affecting children below the age of five years ${ }^{1}$. 
It is still a major childhood killer with over 30 million cases and nearly 900,000 deaths, annually worldwide and about $10 \%$ of all deaths in children under the age of 5 in developing countries ${ }^{2}$. It is now widely recognized that measles vaccination has a definite impact on reduction of not only measles related mortality but also overall mortality in children ${ }^{3,4}$.

Data gathered from several developing countries indicate that measles is not only a major cause of immediate mortality, but that its residual effects contribute to malnutrition and increased mortality from other diseases for many subsequent months ${ }^{5}$. The widespread use of measles vaccine in many developed countries has resulted in greater than $90 \%$ reduction from peak reporting ${ }^{6}$; in contrast, little success has been observed in many developing countries ${ }^{7}$.

In United States measles was dramatically reduced by 1983 after immunization programmes started in 1963. However from 1989 to 1991, measles appeared to be on the rise again as a result of new outbreaks, necessitating a revision in national immunization schedule. It was urged that a second dose of measles vaccine be administrated to school aged children especially those living in crowded urban areas. Benefits were soon apparent as measles fell to lowest levels ever reported of 301 confirmed cases in year $1995^{8}$.

Twice vaccinated have better protection against epidemic measles as compared to single dose recepient ${ }^{9}$. Re-vaccination is recommended at the age of 11-12 years by the American Academy of Paediatrics and before entry to school (4-6 years). However vaccination at 6 months of age followed by routine revaccination is recommended when exposure of infants to measles is likely?.

According to $\mathrm{WHO}$ vaccination coverage for measles in Pakistan at 01 year of age has increased from $56 \%$ in 1995 to $81 \%$ in year $1999^{10}$ but it still remains a major killer disease in children $<5$ years in Pakistan. Federal government reported in 1985 that $80 \%$ of the measles cases occurred in people who have been vaccinated.
Studies carried out at Allied Hospital Faisalabad ${ }^{11}$ in 1992 and Mayo Hospital Lahore ${ }^{12}$ in 1998 concluded that in order to reduce measles mortality there is need for booster doses or a two-dose vaccination schedule for areas with high measles transmission.

Epidemiological phenomena are far from static. Updating knowledge of the status of measles is necessary in order to achieve better understanding and control of this childhood killer disease. Clinical experience suggests that measles is very much prevalent in our vaccinated children who follow the in vogue vaccination schedule.

This study was implemented with the aim to know the intensity of problem in depth and to ascertain the true gravity by calculating the frequency of vaccinated children among measles cases and determining association of age and sex with vaccination status. This will help in explaining the primary vaccine failures and need for re-vaccination schedules so that future work can be built on this to promote and improve measles control.

\section{MATERIALS AND METHODS}

This Descriptive time limited study was carried out at Military Hospital (MH), Rawalpindi from October 2001 to September 2002. A total of 250 cases reporting in out patient department or admitted were selected by convenient sampling technique and registered.

Children between 1 to 12 years of age having measles confirmed clinically by two paediatricians on basis of typical maculopapular rash or pathognomonic koplik's spots in the absence of any systemic illness were included in the study. However Children who developed measles within 4 weeks of measles vaccination or those who have received booster doses of measles or MMR vaccines were excluded. Also Immunocompromised children and children with other causes of rash like drug induced, roseola, rubella and others as evidenced by history and clinical examination were not included in the study. Parental consent was obtained for inclusion of their children in the subject study. 
Data was collected and recorded on a performa which contained patient's particulars, details about rash and vaccination and relevant physical examination at time of registration. History of measles vaccination was ascertained either by checking the vaccination cards or on parental recall. The total group was divided into four equal age intervals of three years each.

Data was analyzed by using the Statistical Package for Social Sciences (SPSS version 10.0, Inc. Chicago, IL). The descriptive statistics were used to calculate frequencies. "t test" was applied to find the statistical significance of difference for numerical data while "chi square" was used for categorical data. Test of significance was applied at a confidence limit of $95 \%$. Due approval was taken from the Ethical Review Committee of MH Rawalpindi to conduct the study.

\section{RESULTS}

A total of 250 cases of measles were studied. Approximately two third of these had been vaccinated before onset of measles $(71.6 \%)$ and rest were unvaccinated $(28.4 \%)$.

Ages ranged from 1 year to 12 year with a mean age of $5.4 \pm 2.4$ years. Vaccinated cases had a higher mean age $(5.9 \pm 2.1)$ as compared to unvaccinated ones $(4.0 \pm 2.5)$. The difference was statistically significant at $p$ value $<0.05$ by applying "t" test (Table I).

\begin{tabular}{|c|c|c|c|}
\hline \multirow[t]{2}{*}{ Vaccination status } & \multirow{2}{*}{$\begin{array}{l}\text { Age (years) } \\
\text { (Mean } \pm S D \text { ) }\end{array}$} & \multicolumn{2}{|c|}{ Gender } \\
\hline & & Males & Females \\
\hline Vaccinated $(n=179)$ & $5.9 \pm 2.1$ & 199 & 80 \\
\hline Unvaccinated $(n=71)$ & $4.0 \pm 2.5^{*}$ & 44 & 27 \\
\hline Total $(n=25)$ & $5.4 \pm 2.4$ & $144^{* *}$ & 107 \\
\hline \multicolumn{4}{|c|}{$\begin{array}{l}\text { *The difference is statistically significant at } p<0.05 \text { by applying } \\
\qquad t \text { " test. } \\
\begin{array}{l}{ }^{* *} \text { The proportion of males was significantly more at } p \text { value } \\
<0.05 \text { than females in both groups. }\end{array}\end{array}$} \\
\hline
\end{tabular}

The highest proportion of cases (46\%) was in the age group 4-6 years. Among vaccinated children almost half of the patients $(50.3 \%)$ were in the age group 4-6 years but among the unvaccinated population more than half of the patients $(52.1 \%)$ fell into $1-3$ years age group (Table II).

\begin{tabular}{|l|c|c|}
\hline \multicolumn{2}{|c|}{ Table-II. Distribution according to age groups $(\mathbf{n = 2 5 0 )}$} \\
\hline $\begin{array}{l}\text { Age groups } \\
\text { (years) }\end{array}$ & $\begin{array}{c}\text { Vaccinated } \\
(\mathbf{n}=179)\end{array}$ & $\begin{array}{c}\text { Unvaccinated } \\
(\mathbf{n}=71)\end{array}$ \\
\hline $1-3$ & $33(18.4)^{*}$ & $37(52.1)$ \\
\hline $4-6$ & $90(50.3)$ & $25(35.2)$ \\
\hline $7-9$ & $45(25.2)$ & $6(8.5)$ \\
\hline $10-12$ & $11(6.1)$ & $3(4.2)$ \\
\hline \multicolumn{3}{|c|}{${ }^{*}$ Figures in parenthesis are percentages } \\
\hline
\end{tabular}

Out of the total population 143(57.2\%) were males and $107(42.8 \%)$ were females with a male to female ratio of 1.4:1. Also the proportion of males was significantly more ( $p$ value $<0.05)$ than females in both vaccinated (1.2:1) and unvaccinated (1.6:1) groups (Table I).

\section{DISCUSSION}

Measles vaccine was introduced in Pakistan in 1978. Vaccination coverage was as low as $56 \%$ in $1995^{10}$. However, after accelerated immunization activities, the 1999 survey showed that measles vaccination coverage had reached $81 \%{ }^{10}$.

Despite the high coverage rate, measles cases are reported every year in Pakistan. The present study revealed that the majority of cases i.e., $71.6 \%$ had histories of measles vaccination and $28.4 \%$ were unvaccinated. The results are similar to those of study by Masoud et al in Egypt where $79.4 \%$ cases of measles were previously vaccinated ${ }^{13}$. Similar results were obtained by Nsungu M in Zimbabwe where $69 \%$ of the cases during a measles outbreak were vaccinated ${ }^{14}$. Like wise Chaudhry MZ found $50 \%$ of cases to be vaccinated in a study carried out at Allied Hospital Faisalabad ${ }^{12}$. In 
surveillance studies by Ashraf $\mathrm{M}^{15}$ in Bahawalpur and Khan $\mathrm{HI}^{12}$ in Lahore found $28 \%$ and $32 \%$ of the cases of measles respectively to be vaccinated.

Similar results of vaccine failure were obtained in epidemiological studies done in various WHO regions. Thakur JS et al during a measles outbreak in India documented $48.8 \%$ of the cases to be vaccinated ${ }^{16}$. During measles epidemic in Australia Leeb A found that $45 \%$ of the cases were previously vaccinated ${ }^{17}$. Slater PE et al during a measles epidemic in Israel found vaccine failure in $37 \%$ cases $^{18}$.

Our findings raise concern about vaccination failure. Reports of large numbers of cases of measles among vaccinated children risk loss of confidence in the programme and may lead to a lack of community motivation seeking and supporting vaccination programmes.

As immunization coverage increases, a higher proportion of cases will occur among immunized children ${ }^{19}$. The role of vaccine failure in developing countries, however, is often difficult to assess due to poor documentation of immunization $^{20}$. Whatever the reasons for these differences, the vaccination failure rate is clearly higher than that accepted for measles vaccine. The accepted failure rate is in the range of $2 \%$ to $10 \%{ }^{21}$.

Vaccination failure may be due to immunization at less than 1 year of age or administration of nonviable, low potency vaccine that may have been improperly stored or handled ${ }^{22}$. Neutralizing effect of maternal antibodies to suppress the effect of measles vaccine up to 12 months or beyond is widely accepted. Thus giving booster doses of MMR ideally or a measles vaccine minimally at 15 months after a measles vaccine at 9 months is very important $^{23}$

Many studies have found that time since vaccination increases the risk of measles vaccine failure ${ }^{24,25}$. Immunization induced by vaccination may not confer life long immunity and reports of loss of vaccine induced protection have been documented in persons known to be seroconvert after vaccination ${ }^{26}$.

The WHO/EPI recommendation for developing countries is routine administration of a single dose measles vaccine to infants at age 9 months $^{27}$. Cutts $F T$, suggested that in developing countries, where measles vaccine is usually administered at age 9 months, approximately $15 \%$ of children are not protected, and vaccine failures can be expected to play an increasing role in outbreaks in the future ${ }^{28}$.

Many studies ${ }^{29,30}$ have urged the need for two dose vaccination schedule to achieve elimination and eradication goals against measles and found that twice vaccinated are better protected against epidemic measles than single dose recipient ${ }^{9}$.

The majority of measles cases in the present study were in the age group of 5 to 12 years $(65.2 \%)$. This is consistent with that reported by Masud $\mathrm{GM}$ et $\mathrm{al}^{13}$ in Egypt and Kamel et $\mathrm{al}^{31}$ in Saudi Arabia in which 69.1\% and $68.61 \%$ of the reported cases of measles were in the same age group respectively. Egemen et al in an epidemiological study in Turkey also found that majority of the cases were in age group 5-9 years ${ }^{32}$. Despite the fact that school-aged children are less prone to the occurrence of complications but they may act as important source of infection for younger siblings who are more vulnerable to complications and mortality ${ }^{20}$. This necessitates increase of vaccination coverage among school-aged children and further justifies the need for two doses of measles vaccine with the second dose given on school entry ${ }^{19}$.

The results of the present study revealed that the mean age of measles cases was $5.4 \pm 2.4$ years. This finding is similar to that reported by Masoud GM et al ${ }^{13}$ in Egypt and Kamel et $\mathrm{al}^{31}$ in Saudi Arabia who found mean ages $6.4 \pm 4.7$ years and $6.1 \pm 4.38$ years respectively. It was higher than that found by Khan AM in a study carried out at children Hospital Islamabad where $40 \%$ of cases were under 1 year of age $^{33}$. The shift in the age distribution of measles cases towards older children is one of the major effects of immunization programmes ${ }^{19}$. The severity of 
measles is well documented among young children; among older children, the disease exhibits a lesser degree of severity. Thus, the shift from younger to older children reduces the overall measles mortality and is a positive impact of immunization programmes. However, the serious consequences of infection among adults should be considered after attaining high coverage rates.

In the present study, the mean age of vaccinated cases $(5.9 \pm 2.1$ years) was significantly $(p<0.05)$ higher than that of unvaccinated cases $(4.0 \pm 2.5)$ with more than half $(52.1 \%)$ of the unvaccinated population in $1-3$ years age group. This was in contradiction to that found by Masoud $\mathrm{GM}$ et $\mathrm{al}^{13}$ where mean age of unvaccinated cases was nearly as high as that for the vaccinated cases $(6.5 \pm 5.1$ and $6.8 \pm 4.1$ years, respectively).

The present study demonstrated a predominance of males $(57.2 \%)$ as compared to females $(42.8 \%)$. It was also found that the proportion of males was significantly more $(p<0.05)$ than the females in both the vaccinated and the unvaccinated groups. Thakur JS in India also found similar proportions i.e. $54 \%$ males as compared to $46 \%$ females $^{16}$. Similar results were found in various studies done in Pakistan. Salahudin in NWFP found $56 \%$ males and $46 \%$ females ${ }^{1}$ and Chaudhry MZ found male to female proportions of $72.3 \%$ and $27.7 \%$ respectively ${ }^{12}$. However Masoud GM et al ${ }^{13}$ documented predominance of females among cases of measles (58.8\%) over males $(41.2 \%)$. Khan $\mathrm{HI}^{12}$ also found that $56.5 \%$ of the cases were females and $43.5 \%$ were males. But the fact is that sex does not affect susceptibility to measles ${ }^{7}$.

\section{CONCLUSION}

Vaccination failure rate as observed in this study, that is $71.6 \%$ patients contracting measles despite being vaccinated is clearly higher than that accepted for measles vaccine $(2-10 \%)$. Measles among vaccinated children; where risks loss of confidence in programme may also lead to lack of community motivation and support for vaccination programme.

Though high immunization coverage (>90\%) in the first dose is still crucial for eradication there is need to revise the in-vogue vaccination schedule to reduce incidence of this vaccine preventable disease and so is the measles related morbidity and mortality.

\section{REFERENCES}

1. Salahuddin, Qadir MF, Shah MZ. Epidemiology of measles in NWFP. Pakistan J Med Res 1999; 38(4):1557.

2. Chalmers I. Why we need to know whether prophylactic antibiotics can reduce measles-related morbidity. Paediatrics 2002; 109(2): 312-5.

3. Clemens JD, Stanton BF, Chakarborty S, Rao MR, Ali M. Measles vaccination and childhood mortality in rural Bangladesh. Am J of Epidemiol 1988; 128(6):1330-9.

4. Koenig MA, Khan MA, Wojtyniak B, Clemens JD, Chakarborty J, Fauveau V. Impact of measles vaccination on childhood mortality in rural Bangladesh. Bull World Health Organization 1990; 68 (4):441-7.

5. Aaby $P$, Clements $C J$. Measles immunization research: a review. Bulletin of the WHO 1989; 67(4):443-8.

6. Frank JA et al. Major impediments to measles elimination: the modern epidemiology of an ancient disease. American journal of diseases of children 1985; 139:881-7.

7. Black FL. Measles. In: Evans AS Eds. Viral infections of humans: epidemiology and control. New York: Plenum medical book company 1991; 451-69.

8. Gold E. Current progress in measles eradication in United States. Infect Med 1997; 14 (4): 297-300-310.

9. Hutchins SS et al. Evaluation of an early two-dose measles vaccination schedule. Am J Epidemiol 2001; 154(11):1064-71.

10. "World Health Report, 1999", Geneva. World Health Organization 1999:4-34.

11. Chaudhry MZ, Ali N, Mustansar M, Khan GA. Impact of EPI on poliomyelitis and measles. Specialist 1994; 10(2):93-8.

12. Khan HI, Ahmed TJ. Risk factors for increased mortality in children with complications of measles. JCPSP 1999; 9(6):247-250. 
13. Masoud GM. Sero-epidemiological study of measles after 15 years of compulsory vaccination in Alexandria, Egypt. Alexandria journal of pediatrics, 1998; 4(3): 437-447.

14. Nsungu M. Measles vaccination status, delay in recognizing measles outbreaks and outbreak outcome. Cent Afr J Med 1995;41(11):336-9.

15. Ashraf M. Survelliance of infectious diseasesin Bahawalpur Victoria Hospital. Pak Paed J 1987; 12:31-36.

16. Thakur JS, Ratho RK, Bhatia SP, Grover R, Issaivanan M, Ahmed $B$ et al. Measles outbreak in a Periurban area of Chandigarh: need for improving vaccine coverage and strengthening surveillance. Indian J Pediatr 2002; 69(1):33-7.

17. Leeb A. Measles vaccination failure-cause for concern? Aust Fam Physician 1992; 21(3):297-301, 304.

18. Slater PE, Roitman M, Costin C. The 1991 measles epidemic in Israel. Public Health Rev 1992-93; 20 (12):41-51.

19. Global programme for vaccines and immunization. Immunization policy. Geneva, WHO, 1995.

20. Expanded programme on immunization. Measles control in the 1990s: principles for the next decade. Geneva, WHO, 1990, 3-42.

21. Wilkins J, Wehle PF. Evidence for reinstatement of infants 12 to 14 months of age into routine measles immunization programs. American journal of diseases of children 1978; 132:164-6.

22. Brunell PA. Antibody response following measlesmumps-rubella vaccine under conditions of customary use. Journal of the American Medical Association 1983, 250(11):1409-12.

23. Mathew A. Misguiding Guidelines from IAP? Indian Pediatrics 2000;37: 1141-46.
24. Robertson SE, Markowitz LE, Berry DA. A million dollar measles outbreak - epidemiology, risk factors, and a selective revaccination strategy. Public Health Rep 1992; 107:24-31.

25. Yuan L. Measles outbreak in 31 schools: risk factors for vaccine failure and evaluation of a selective revaccination strategy. Can Med Assoc J 1994; 150:1093-8.

26. Reys MA. Measles vaccination failure after documented seroconversion. Paed Infect Dis Jour $1987 ; 6: 848-9$

27. Lerman SJ, Gold E. Measles in children previously vaccinated against measles. Journal of the American Medical Association1971; 216(8):1311-4.

28. Cutts FT, Dabis F. Measles control in developing countries. Sante 1994; 4(3):163-71.

29. Suresh K, Saxena D. Trends and determinants of immunisation coverage in India. $J$ Indian Med Assoc 2000 Jan; 98(1):10-4.

30. Al-Mazrou YY. Sero-response to measles-mumpsrubella vaccine campaign in Saudi Arabia. Saudi Med J 2002; 23(6):680-3.

31. Kamel MI. Comparison of some epidemiological characteristics of vaccinated and unvaccinated measles cases in Saudi Arabia. Alexandria journal of pediatrics, 1989, 3(4):545-2.

32. Egemen A, Tasdemir I, Eker L, Arcasoy M. Changing epidemiology of measles in Turkey: need for reassessment of measles vaccination policy? J Trop Pediatr 1996; 42(5):299-301.

33. Khan AM, Rehman NG. The Children Hospital: a profile of infectious diseases. Pak Paed J 1989; 13 (3):165173. 